\title{
TRANSITIVIDAD EN EL DISCURSO BRIBRI
}

\author{
Carla Victoria Jara
}

\begin{abstract}
The "Transitivity Hypothesis" set forth by Hopper and Thompson (1980) is discussed in regard to the Bribri (Chibchan) language. The transitivity phenomenon is analized at semantic, syntactic and discourse levels with the ultimate goal of establishing the predictive power of the hypothesis.
\end{abstract}

\section{Introducción}

En este artículo se discute, en relación con el discurso bribri, la hipotesis sobre transitividad propuesta por Paul Hopper y Sandra Thompson (1980). El fenómeno de transitividad se analiza en tres niveles: semántico, sintáctico y discursivo. El objetivo es evaluar la veracidad de la hipótesis.

La transitividad puede caracterizarse en general como el proceso por medio del cual algún tipo de acción es transferida de un participante a otro. La transitividad así definida es por lo tanto un fenómeno semántico, pero lo que la hace un factor central en el lenguaje humano es el hecho de que la codificación de este fenómeno semántico tiene consecuencias morfosintácticas fundamentales en el nivel gramatical de cualquier lengua. La contribución de Hopper \& Thompson (1980) es señalar que la transitividad no solo tiene implicaciones en el nivel gramatical sino que las propiedades mismas que la definen están determinadas a nivel de discurso.

\section{Transitividad a nivel semántico}

La esencia semántica de la transitividad es que ciertas proposiciones se refieren a un cambio en el tiempo que involucra directamente dos entidades. Un cambio en el tiempo implica un predicado del tipo llamado evento ("¿qué sucedió?") y una entidad, argumento o participante que ha sufrido el cambio y que es llamado paciente de cambio. Cuando el cambio ha sido causado por algún argumento identificable, este es llamado agente y el tipo de evento se considera una acción. Por lo tanto, el marco proposicional de una oración transitiva implica los siguientes elementos: 
1. un predicado de acción: un evento para el cual un agente responsable es identificado.

2. un agente: un argumento/participante responsable de iniciar el cambio.

3. un paciente de cambio: un argumento/participante que sufre el cambio.

El cambio de un argumento/participante en el tiempo por si solo no implica la codificación transitiva; solo se codifica como transitivo si hay en la oración un agente identificable. Considérese el siguiente ejemplo:

(1) HERVIR: cambio en el tiempo

$\begin{array}{ll}\text { evento: } & \begin{array}{l}\text { El agua / hierve } \\ \text { paciente / evento } \\ \text { de cambio }\end{array} \\ \text { acción: } & \begin{array}{l}\text { Elisa / hierve / el agua } \\ \text { agente / acción / paciente }\end{array}\end{array}$

de cambio

Con base en estos elementos podemos definir la transitividad semántica como el proceso por el cual determinada acción es transferida de un agente a un paciente de cambio.

En la sintaxis funcionalista, la transitividad es considerada como un continuo que va de eventos menos prototípicamente transitivos hasta acciones altamente transitivas. Givón (1984) caracteriza la transitividad prototípica como una situación en la cual se dan las siguientes condiciones prototípicas:

1. Presencia de un agente visible, controlador y volitivo.

2. Presencia de un paciente visible y registrador del cambio.

3. Verbo transitivo que implica un cambio físico y discernible.

Hopper \& Thompson añaden una lista de componentes a la transitividad prototípica, los cuales tienen que ver con la efectividad con la cual el cambio se realiza, a saber, puntualidad y perfectividad semánticas del verbo, grado de conciencia y volición del agente, y afectación e individualidad del paciente. Incluyen también como aspectos prototípicos de la transitividad, la polaridad afirmativa y el modo realis. Esto implica que una oración como "Elisa hirvió el agua" (aspecto perfectivo, polaridad afirmativa y modo realis) es más prototípicamente transitiva desde el punto de vista semántico que las siguientes (a pesar de que desde el punto de vista sintáctico todas son oraciones transitivas):

(2) Elisa hierve el agua (aspecto imperfectivo).

Elisa no hirvió el agua (polaridad negativa).

Elisa talvez hierva el agua (modo irrealis). 


\section{Transitividad a nivel sintáctico}

En la sintaxis funcionalista, el dominio gramatical es considerado como un estadio codificador intermedio entre la semántica y el discurso. La codificación de proposiciones semánticamente transitivas varía de lengua a lengua. Por ejemplo, las lenguas pueden presentar diferentes sistemas de morfología flexiva para los verbos dependiendo de si son transitivos o no. Un caso es la lengua bribri, que presenta dos clases morfológicas de verbos: la transitiva y la intransitiva (Constenla y Margery 1979). Estas clases son discretas, en el sentido de que cada verbo pertenece exclusivamente a una o a la otra, a diferencia del español (cf. (1) supra). La marcación morfológica de la transitividad es común en las lenguas del mundo.

En el nivel sintáctico, la transitividad tiene profundas consecuencias en la manera en que los principales argumentos de la cláusula -agente y paciente- son codificados, y particularmente en la manera en que esta codificación se hace concordar con los casos pragmáticos de sujeto y objeto directo de la oración. Las lenguas necesitan codificar conjuntamente las funciones semántica y pragmática del caso. De esta necesidad surge un vínculo funcional entre el caso semántico y el caso pragmático de los argumentos de la cláusula. Los diferentes sistemas de marcación de casos son soluciones tipológicas al mismo vínculo funcional (Givón 1984:136).

Existen básicamente tres maneras en que las lenguas del mundo responden a esta necesidad:

1. En el sistema de marcación de casos nominativo-acusativo, no importa cuál sea el caso semántico del sujeto: puede ser agente o paciente, en ambas situaciones se codifica de la misma forma, como en español: El hombre cortó la carne. El hombre murió. En español, el recurso gramatical relevante para codificar sujeto y objeto directo es en estos ejemplos el orden de palabras: el sujeto aparece en posición preverbal y el objeto directo aparece en posición posverbal.

2. En el sistema activo-no activo, el sujeto agente es codificado de manera diferente al sujeto no agente: no importa si el verbo es transitivo (es decir, si tiene objeto directo) o intransitivo. El bocotá, lengua chibcha de Panamá, pertenece a este tipo (Jara 1989):

(3a) Cha gugédu

yo quemar.PRET.NO-ACT ${ }^{1}$

'Yo me quemé (accidentalmente).'

b) Cha no gliá gúgle

yo AGENTE hoja quemar.PRET.ACT

'Yo quemé hojas.'

c) Cha no mon gúgle

yo AGENTE REFLEX quemar.PRET.ACT

'Yo me quemé (deliberadamente).' 
Cuando cha 'yo' es agente lleva la marca no 'marcador de agente', cuando no lo es, entonces no se marca como tal; en los tres ejemplos, 'yo' está en el caso pragmático de sujeto.

3. En el sistema ergativo-absolutivo, el parámetro relevante es la transitividad del verbo: si el verbo es transitivo su objeto directo se marca como caso absolutivo; si es intransitivo, su sujeto se marca igualmente como caso absolutivo. Esto quiere decir que el objeto directo de verbo transitivo y el sujeto de verbo intransitivo son considerados como el mismo caso y por tanto se codifican ambos como caso absolutivo. Por otra parte, el sujeto de verbo transitivo se codifica como caso ergativo. El bribri es un ejemplo de este tipo:

$$
\begin{aligned}
& \text { Ye' tö i che. } \\
& \text { yo ERG eso decir.IMP } \\
& \text { 'Yo lo decía.' }
\end{aligned}
$$

$$
\text { Ie' tse. }
$$

él cantar.IMP

'El cantaba.'

Aquí $i$ 'eso' y ie' 'él' están en el caso absolutivo, codificado por orden de palabras: posición preverbal, mientras que ye' 'yo' está en el caso ergativo, marcado morfológicamente por medio de la posposición tö.

En resumen, las lenguas activas optan por el caso semántico del argumento: el agente es el caso marcado, mientras que el paciente es en general no marcado. Otras lenguas codifican de forma diferente los casos de agente, paciente y sujeto: las lenguas nominativas-acusativas codifican conjuntamente agente y sujeto (caso sujeto) en oposición al paciente (caso objeto directo); las lenguas ergativas-absolutivas codifican conjuntamente sujeto intransitivo y paciente (caso absolutivo), en oposición al sujeto transitivo/agente (caso ergativo). Esto revela que la codificación sintáctica de los casos está íntimamente relacionada con el fenómeno de la transitividad.

\section{Transitividad a nivel de discurso}

\subsection{La Hipótesis de Transitividad de Hopper \& Thompson}

El punto de vista de la sintaxis funcionalista (Givón, particularmente) es que la prágmatica del discurso y la topicalidad de un participante (el tópico es el argumento más continuo/obvio de la cláusula) determinan la interpretación de los eventos transitivos. La dicotomía artificial entre transitividad semántica y pragmática se resuelve gracias a la noción de prominencia/topicalidad/obviedad. El tópico del discurso, el caso semántico de agente y el caso prágmatico de sujeto tienden a coincidir en un mismo argumento de la cláusula. El caso pragmático del sujeto se define en el discurso como la tendencia natural en el lenguaje humano de hacer coincidir 
tópico y agente, mientras que el sujeto gramatical es la gramaticalización de esta coincidencia (Comrie 1981:114).

Tradicionalmente se ha considerado la transitividad como un fenómeno de la cláusula. Hopper \& Thompson afirman que las propiedades definitorias de la transitividad están también determinadas por el discurso y le señalan los siguientes componentes:

Tabla 1

COMPONENTE
1- Participantes:
2- Kinesis:
3- Aspecto:
4- Puntualidad:
5- Volición:
6-Afirmación:
7- Modo:
8- Agentividad:
9-Afectación:
10-Individualidad:

RASGOS

2/ 1 participantes

+1 -acción

$+/$ - perfectivo

$+/$ - puntual

$+/$ - volitivo

+1 - afirmativo

+1 - realis

$+/$ - alta agentividad

+ / - objeto afectado

objeto individualizado

/objeto referencial

En la Tabla 1, los rasgos a la izquierda son altos en transitividad y los rasgos a la derecha son bajos en transitividad. El punto principal de Hopper \& Thompson es que la transitividad es una acción efectiva de alguna forma.

La hipótesis de la transitividad establece que si dos cláusulas (a) y (b) difieren en que (a) es más alta en transitividad que (b) en cualquiera de los diez parametros establecidos en la Tabla 1, y si además existe una diferencia gramatical o semántica concomitante entre las dos cláusulas, esta diferencia también mostrará que (a) es más alta en transitividad que (b) (Hopper and Thompson 1980: 255). La propuesta implica que, en su conjunto, los rasgos permiten caracterizar las clásulas como MAS o MENOS transitivas: cuantos más rasgos altos en transitividad tenga una cláusula, más transitiva es la cláusula, es decir, más cerca estará a la transitividad cardinal.

Para Hopper \& Thompson, esta caracterización obedece a un marco preteórico, ya que la verdadera dimensión de la transitividad no reside en la cláusula. Afirman que esta propiedad central del lenguaje adquiere real significado al nivel del discurso: la transitividad es baja en las porciones de discurso que conllevan información de segundo plano (background) y alta en las porciones que conllevan información de primer plano (foreground). Me referiré a este aspecto más abajo. La hipótesis de la transitividad aún opera al nivel de la cláusula.

En bribri, se puede señalar por lo menos un contraejemplo a la hipótesis de la transitividad, en relación con el uso de formas verbales más vs. menos transitivas. Antes, deben considerarse los siguientes aspectos:

Primero, dos voces han sido identificadas en esta lengua: activa e indefinida (Constenla y Margery 1979:59). En voz activa, el sujeto de un verbo transitivo se marca como ergativo, como ya se dijo. En voz indefinida, los verbos toman solamente el argumento paciente, el cual se codifica como absolutivo; el caso ergativo es imposible en voz indefinida. 
Segundo, el bribri distingue morfológicamente dos aspectos: perfectivo e imperfectivo, tanto en voz activa como en voz indefinida.

Tercero, mientras que en cláusulas afirmativas tanto imperfectivas como perfectivas la conjugación verbal corresponde a la voz activa, en las cláusulas negativas perfectivas los verbos transitivos deben conjugarse en voz indefinida (Constenla y Margery 1979).

Estos hechos se reflejan en los siguientes ejemplos:

(6) Ye' tö i ñè.

yo ERG eso comer.IMP.ACT

'Yo lo comía.'

(7) Ye' tö i ña'.

yo ERG eso comer.PER.ACT

'Yo lo comí.'

(8) Kè̀ ye' tö i ñè.

NEG yo ERG eso comer.IMP.ACT

'Yo no lo comía.'

(9) Kè̀ ye' wa i ñàne.

NEG yo AG eso comer.PER.INDEF

'Yo no lo comí.'

Esto significa que la forma verbal en una cláusula negativa perfectiva activa debe ser seleccionada del paradigma de voz indefinida:

(10) ñár (IMP.INDEF) 'se come'

ñàne (PER.INDEF) 'fue comido'.

Por otra parte, las cláusulas negativas en voz indefinida se comportan de manera regular, en el sentido de que se codifican de acuerdo con el correspondiente paradigma de voz indefinida:

(11) Kè̀ i ñár

NEG eso comer.IMP.INDEF

'Eso no se comía.'

(12) Kè̀ i ñàne

NEG eso comer.PER.INDEF

'Eso no fue comido.'

En relación con la hipótesis de la transitividad, puede verse que algo en estos datos no se ajusta a la predicción de la hipótesis. En Bribri, el aspecto perfectivo y la transitividad no 
pueden ser codificadas simultáneamente en una cláusula cuando esta es negativa. Para mostrar esto, compárense las cláusulas (8), (9) y (11) repetidas abajo como (13):

(13a) Kè̀ ye' wạ i ñàne 'Yo no lo comí.'

b) Kë i ñàr. 'Eso no se comía.'

c) Kè̀ e' dör i ñè. 'Yo no lo comía.'

Para demostrar cómo este conjunto de cláusulas constituye un contraejemplo a la hipótesis de transitividad, examínense los parámetros relevantes que aparecen en ellas:

Tabla 2

$\begin{array}{llll} & \text { a) } & \text { b) } & \text { c) } \\ \text { Participantes } & 2 & 1 & 2 \\ \text { Perfectividad } & \text { perfectivo } & \text { imperfectivo } & \text { imperfectivo } \\ \text { Agentividad alta (=Ergativo) } & \text { no ergativo } & \text { no ergativo } & \text { ergativo }\end{array}$

De acuerdo con la hipótesis, (13b) y (13c) se ajustan a la predicción, ya que (13c) es más alta en transitividad en el rasgo de participantes, y hay una "diferencia gramatical concomitante" que también refleja mayor transitividad, esto es, el verbo aparece en voz activa y por lo tanto el agente está marcado como ergativo. Sin embargo, al comparar (13a) y (13c), vemos que (13a) es más alta en transitividad de acuerdo con el rasgo aspecto, pero hay también una diferencia gramatical concomitante la cual, contrario a lo que predice la hipótesis, caracteriza a (13a) como más baja en transitividad, ya que siendo el verbo obligatoriamente codificado en voz indefinida, su agente no puede ser marcado como ergativo sino como un caso oblícuo marcado por la posposición wa.

Desde luego, este contraejemplo puede desecharse si se arguye que las clásulas negativas no constituyen el mejor ejemplo para mostrar el funcionamiento de la transitividad prototípica; sin embargo, puede sostenerse que, de acuerdo con la manera en que la hipótesis está planteada, el ejemplo del bribri definitivamente constituye una excepción. Para resolver este problema, la hipótesis debiera replantearse de modo que reconozca que no se aplica al menos universalmente cuando las cláusulas comparadas son negativas.

Por otra parte, quizás el contraejemplo aquí presentado puede utilizarse no como argumento para desechar la hipótesis, sino por el contrario, para sustentarla, ya que parece confirmar que la transitividad prototípica es un fenómeno relacionado con hechos ocurridos, por lo que más frecuentemente implica cláusulas realis afirmativas perfectivas, las idóneas para codificar la transferencia de acción de un argumento a otro. 


\subsection{Transitividad en el discurso de primer plano vs. el discurso de segundo plano}

Según Hopper \& Thompson, las cláusulas de primer plano establecen la estructura temporal de la narrativa: conllevan la secuencia de los eventos, los cambios de estado y, en general, la línea principal del discurso, al establecer "que sucedió". La cláusulas de segundo plano son las que proveen la estructura durativa/descriptiva de la narrativa, y dan contexto espacial y caractereológico:

The foregrounded portions together comprise the backbone or skeleton of the text, forming its basic structure; the backgrounded clauses put flesh on the skeleton, but are extraneous to its structural coherence. (Ibid:281) ${ }^{1}$

Los autores afirman que el discurso de primer plano implica un mayor grado de transitividad que el discurso de segundo plano:

The likelihood that a clause will receive a foreground interpretation is proportional to the height of that clause on the scale of Transitivity. From the performer's viewpoint, the decision to foreground a clause will be reflected in the decision to encode more (rather than fewer) Transitivity features in the clause. (Ibid:284) ${ }^{2}$

El propósito de esta sección es establecer si la afirmación de Hopper \& Thompson acerca de la correlación transitividad-discurso se refleja en la lengua bribri. En otras palabras, se pretende establecer una correlación entre las cláusulas transitivas de un texto y su aparición como cláusulas de primer plano o de segundo plano.

En el análisis del texto -una porción de Tcho'dawe 'Los diablos del bosque' (Jara 1993: 154-60)-, se aplicaron estrictamente las definiciones de Hopper \& Thompson de discurso de primer plano y discurso de segundo plano; además, las cláusulas del narrador que introducen discurso de los personajes fueron consideradas como de primer plano, pero el discurso propiamente de los personajes y las repeticiones fueron omitidas del conteo. De acuerdo con estos criterios, el texto incluye 45 cláusulas que contienen información de primer plano y 34 que contienen información de segundo plano.

En la siguiente porción del texto (inicio), las cláusulas de primer plano aparecen en cursiva y las de segundo plano en tipo normal:

(14a) E' kè̀ pata ie' tö íyök yawè

DEM después $3 S$ ERG tierra hacer.IMP

Después de haber hecho la tierra (Sibö)

b) $e^{\prime} \quad$ tsó awéne ie tö se'ditsò̀

DEM primero hacer.IMP $3 S$ ERG 1P semilla

él creó a los primeros seres, 
c) e' rö Kóbala.

DEM COP Kóbala

que fueron los Kóbala.

d) Lò̀ neka $\underline{a} \underline{a}$.

multiplicarse.IMP mucho

Estos se multiplicaron mucho,

e) $\quad$ ema erë ie' $i$ mowène .

PROG CONJ 3S 3P probar.IMP

pero entonces él los probó.

f) Ie' kị i kiàne i mọsopa ia katànok, yànok.

$3 \mathrm{~S}$ sobre $3 \mathrm{~S}$ querer.PER $3 \mathrm{~S}$ ayudante.PL para comida.FIN bebida.FIN

Los quería como alimento y bebida para sus ayudantes.

g) Kè̀ i di bua',

NEG 3P COP bueno

No eran buenos,

h) ák wồchaka è i di.

piedra pura solamente 3P COP

eran pura piedra.

i) E' kuék ie'tö e' è̀we wạ,

DEM por $3 S$ ERG DEM exterminar.IMP

Por eso los exterminó.

j) êma e' bùkàmị wì di' a

PROG DEM lanzar.PER DEM agua en

lanzándolos al agua.

k) $E^{\prime} \quad$ skè tsakine $\underline{i} d i$

DEM otro crear.PER 3S ERG

Entonces creó otros seres

1) e' rö Tcho'dawe.

DEM COP Tchó'dawe

que fueron los Tcho'dawe.

m) Tcho'dawe bák ie'pa ñù wàbalök sulüë,

Tcho'dawe AUX 3P REC pelear.INF mal.INT

Los Tcho'dawe peleaban mucho entre ellos, 
n) ie'pa s ttèkèlur, 3P 1P matar.IMP.PL se mataban,

o) ie'pa s tchèkèlur ikè wa. 3P 1P punzar.IMP.PL lanza con se punzaban con lanzas.

Con respecto a la porción aquí transcrita, 6 cláusulas (14b, d, e, i, k, m) conforman el discurso de primer plano, de las cuales la mitad (b, i, k) son marcadas como transitivas (con el agente marcado como ergativo), mientras que de las 9 restantes (discurso de segundo plano), solamente una (14a) es marcada como transitiva. El hecho de que sea esta la primera cláusula de la narración le da un estatus especial dentro del discurso total, particularmente considerando el importante factor del discurso bribri de que frecuentemente Sibò̀ no es mencionado por su nombre al inicio de una narración tradicional. El grado de topicalidad de Sibò es tal dentro de esta narrativa, que su nombre se omite, y es referido en cambio por medio del pronombre de tercera persona ie' 'él', es decir de forma exofórica. Probablemente el uso de la exófora sea compensado en la codificación gramatical mediante la marcación explícita del caso ergativo, aun cuando la cláusula conlleve información de segundo plano.

Por otra parte, resulta discutibleble catalogar la primera cláusula del discurso como de segundo plano. La he considerado así en este análisis debido al hecho de que la información que conlleva se refiere a una circunstancia temporal que sirve de contexto al hecho principal: Sibò̀ creó a los primeros seres, hecho de primer plano codificado en una cláusula transitiva (14b). Las dificultades inherentes a la clasificación de clásulas como de primer o segundo plano han sido frecuentemente señaladas dentro del área de análisis del discurso, situación que se comenta más abajo.

Los resultados para el texto total analizado (79 cláusulas) son los siguientes:

De las 45 cláusulas de primer plano, 16 son transitivas; las restantes 29 son clásulas copulativas, estativas o intransitivas. En cuanto a las 34 cláusulas de segundo plano, solamente 2 son cláusulas marcadas como transitivas (incluyendo la primera , cf. (14a) supra). El resultado claramente sustenta la afirmación de Hopper \& Thompson de que la transitividad se correlaciona más fuertemente con el discurso de primer plano que con el discurso de segundo plano. La implicación relevante de esta afirmación es que el uso de estructuras transitivas y no transitivas no es casual ni aleatorio, sino que está claramente determinado por las necesidades del discurso.

La Tabla 3 muestra una comparación numérica y porcentual de los resultados arriba comentados: 
Tabla 3

\section{Cláusulas Transitivas}

Discurso de Primer Plano Discurso de Segundo Plano
$\#$
16 de 45
$35.5 \%$
2 de 34
$5.8 \%$

Esto significa que las clásulas transtivas en este texto bribri aparecen cerca de seis veces más frecuentemente en discurso de primer plano que en discurso de segundo plano.

\subsection{Las ideas de Hopper \& Thompson en la sintaxis funcionalista actual}

Los componentes de la transitividad son avalados en la sintaxis funcional (por ejemplo, véase Givón 1990:963, 967 en cuanto a la evidencia distribucional de las categorías no marcadas de modo realis, aspecto perfectivo y tiempo pretérito, y en cuanto la evidencia de no-arbitrariedad en sintaxis). Sin embargo, algunos de los aspectos de la propuesta han estado sujetos a revisión. Por ejemplo, la distinción entre discurso de primer plano y discurso de segundo plano es extremadamente vaga, y los funcionalistas que han seguido esta línea de análisis del discurso han encontrado sumamente difícil establecer de forma objetiva y sistemática los parámetros para determinar cuándo una cláusula es de primer plano y cuándo es de segundo plano.

Delancey (1987) hace una evaluación de la propuesta de Hopper \& Thompson acerca de la transitividad en el discurso comparando el artículo de George Lakoff "Linguistic Gestalts" (1977) con los parámetros definitorios de la transitividad propuestos por Hopper \& Thompson. Lakoff propone un análisis de la transitividad desde la perspectiva del trabajo de Rosch sobre la categorialización, una aproximación a la semántica basada en la teoría de prototipos. La teoría de prototipos ha sido un marco conceptual generalizado en la lingǘsitica funcionalista a la Givón (cp. Givón 1984). La posición de Delancey es interpretar la transitividad a la luz del modelo semántico de prototipos.

Para Delancey, la principal diferencia entre las dos posiciones es que mientras para Hopper \& Thompson existe una lista de propiedades categóricas que definen la transitividad, en el marco de prototipos la categoría de transitivo es definida:

by a bundle of differentially-weighted features: the more of the relevant features that occur in a particular instance, the better an instance it is of the category, but an instance can lack many of the defining features and still count as an example of the category of transitive event. (Delancey, 1987:58). ${ }^{4}$

Parece injusto de parte de Delancey interpretar la hipótesis de la transitividad como un conjunto de recursos categóricos; se puede apreciar claramente de las citas supra de Hopper \& Thompson que Delancey malinterpreta sus ideas. 
En cualquier caso, lo que importa desde el punto de vista funcionalista es que la transitividad está constituida por una serie de parámetros o rasgos que conjuntamente codifican la transferencia de acción de un participante a otro, y que esta transferencia de acción existe como un continuo y no como un fenómeno discreto, en términos semánticos. Más o menos categorías codificadoras pueden estar presentes de acuerdo con la mayor o menor prototipicidad del evento, hecho este que está incónicamente relacionado con la naturaleza continua de la transitividad.

Un aspecto final digno de mencionar con respecto a la crítica de Delancey es su afirmación de que no es en el dominio del discurso sino en los procesos cognitivos donde debe buscarse la explicación a la prominencia discursiva de las cláusulas altamente transitivas:

It is this notion of psychological salience which will explain the behavior of grammatical transitivity in discourse. Our ultimate goal in the study of discourse as well as of semantics and morphosyntax, should be to find explanations for our data at an extralinguistic cognitive level. (Ibid 67) 5

La esencia de esta diferencia de posiciones pareciera radicar, ante todo, en si se puede resolver la cuestión de dónde se traza la línea divisoria entre discurso y procesos cognitivos, entre lengua y pensamiento. Esta es una cuestión que está lejos de ser resuelta, por lo que resulta razonable estudiar el discurso como un reflejo de los procesos cognitivos a los cuales no tenemos acceso directo.

\section{Notas}

1. Las abreviaturas empleadas en este artículo son las siguientes: ACTivo, AGentivo, AUXiliar, CONJunción, COPula, DEMostrativo, ERGativo, FINalidad, INDefinida (voz), INFinitivo, IMPerfectivo, INTensificador, NEGación, NO-ACTivo, PERfectivo, PLural, PRETérito, PROGresión, RECíproco (pronombre), REFLEXivo (pronombre), 1P primera persona plural, $3 \mathrm{~S}$ tercera persona singular, 3P tercera persona plural.

2. Las porciones de primer plano conforman la espina dorsal o esqueleto del texto, formando su estructura básica; las cláusulas de segundo plano ponen carne al esqueleto, pero son externas a su coherencia estructural.

3. La probabilidad de que una cláusula reciba interpretación como de primer plano es proporcional a la altura de la cláusula en la escala de Transitividad. Desde el punto de vista del emisor, la decisión de poner en primer plano una cláusula se reflejará en la decisión de codificar más (y no menos) rasgos de Transitividad en la cláusula.

4. Por un haz de rasgos diferencialmente ponderados: cuantos más rasgos relevantes aparezcan en un ejemplo particular, mejor será el ejemplo de la categoría; sin embargo un ejemplo puede carecer de muchos de los rasgos definitorios y aun así contar como ejemplo de la categoría de evento transitivo.

5. Es esta noción de prominencia sicológica la que explicará el comportamiento de la transitividad gramatical en el discurso. Nuestro objetivo final en el estudio del discurso así como de la semántica y la morfosintaxis debiera ser encontrar explicaciones para nuestros datos a un nivel cognitivo extralingüístico. 


\section{Bibliografía}

Comrie, Bernard. 1981. Language Universals and Linguistic Typology. Chicago: University of Chicago Press.

Constenla, Adolfo y Enrique Margery. 1979. Bribri II. San José: Universidad de Costa Rica.

Delancey, Scott. 1987. "Transitivity in Grammar and Cognition". En: Tomlin, R.(ed.), Coherence and Grounding in Discourse. Amsterdam: John Benjamins.

Givón, Talmy. 1984. Syntax: A Functional-Typological Approach. Vol 1. Amsterdam: John Benjamins.

Givón, Talmy. 1990. Syntax: A Functional-Typological Approach. Vol 2. Amsterdam: John Benjamins.

Hopper, Paul \& Sandra Thompson, 1980. "Transitivity in Grammar and Discourse". Language. $56,2,251-299$.

Jara, Carla V. 1989. "Categorías en el Sistema Verbal del Bocotá de Chiriquî", Estudios de Lingüistica Chibcha. VIII, 105-140.

Jara, Carla V. 1993. I TTE. Historias Bribris. San José: Universidad de Costa Rica. 